\title{
O Sistema Municipal de Meio Ambiente no Brasil: avanços e desafios'
}

Environmental Municipal System: advances and challenges

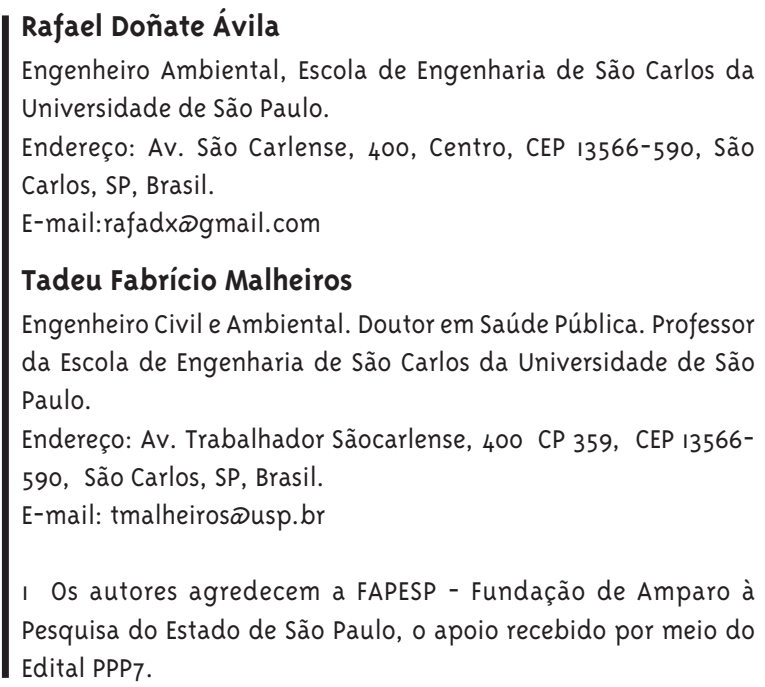

\section{Resumo}

O papel dos governos locais, antes vistos como mero prestadores de serviços, vem evoluindo, pósConstituição de 1988, para o de agentes do desenvolvimento local. Neste contexto, eles devem assumir o seu papel constitucional de zelar pelo meio ambiente, tomando a decisão de envolver-se com o tema e capacitando-se através da instituição de um Sistema Municipal de Meio Ambiente - SISMUMA. O SISMUMA é um conjunto de órgãos e entidades do Município que são responsáveis pela preservação, conservação, proteção, defesa, melhoria, recuperação e controle do meio ambiente e uso adequado dos recursos ambientais do Município. Este Sistema é uma estrutura político-administrativa que em última instância visa a inserção do componente ambiental no processo de tomada de decisão local, por meio da formulação, implementação e avaliação de políticas ambientais e integração com outras políticas, considerando a realidade e potencialidade de cada região, em conformidade com os princípios de desenvolvimento sustentável. Este artigo visa caracterizar e contextualizar o SISMUMA no Brasil, discutindo o seu papel estratégico na governança para a sustentabilidade municipal, entendida como processo de articulação e negociação que potencializa a integração do componente ambiental no processo de tomada de decisão local, e consequentemente, no processo de desenvolvimento local.

Palavras-chave: Governo local; Descentralização; Meio ambiente; Planejamento. 


\section{Abstract}

After Brazilian 1988 Federal Constitution, the role of local governments is evolving from being seen as mere provider of services to being the local development agents. In this context, they must assume their constitutional role of looking after the environment, taking the decision of becoming involved in this matter and to qualify themselves by establishing a Environment Municipal System - SISMUMA. The SISMUMA is a group of municipal agencies and entities responsible for the preservation, conservation, protection, defense, improvement, restoration and control of the environment and appropriate use of the environmental resources of the municipality. This system is a political-administrative structure that ultimately aims at the integration of the environmental component in the local decision-making process, through the formulation, implementation and evaluation of environmental policies and integration with other policies. This is done considering the reality and potentiality of each region, in accordance with the principles of sustainable development. This article aims to characterize and contextualize the SISMUMA in Brazil, discussing its strategic role in municipal governance for the sustainability, role known as an articulation and negotiation process which reinforces the environmental integration component in the local decisionmaking, and consequently in the local development process.

Keywords: Local Government; decentralization; Environment; Planning.

\section{Introdução}

A municipalização da questão ambiental é apontada como um passo evolutivo importante na gestão ambiental descentralizada e na institucionalização da participação popular, aspectos consagrados em 1988 pela Constituição Federal mas previstos desde 1981, com a instituição da Política Nacional de Meio Ambiente (Lei Ordinária 6.938) (Brasil, 1981). Em nível local, a autoridade e o poder de decisão estão próximos da população, e conhecem melhor seus interesses e problemas cotidianos, facilitando uma maior participação da sociedade no equacionamento e solução dos problemas ambientais. Hoje "o Município torna-se local privilegiado para o tratamento da problemática socioambiental que afeta diretamente a sociedade em seu dia a dia, tornando possível que os governos locais encontrem, em conjunto com a sociedade, caminhos saudáveis para seu crescimento, superando o discurso tradicional de progresso a qualquer preço" (Bruschi e col., 2002).

No entanto, dos mais de cinco mil municípios brasileiros, poucos são os que tomaram caminhos sustentáveis e consolidados de gestão ambiental e tratam a questão com o devido empenho. A efetivação dos sistemas locais de meio ambiente demanda que os municípios, por meio de seus governos locais, se fortaleçam enquanto instâncias de planejamento e decisão, o que demanda, portanto, que eles se capacitem para o estabelecimento de políticas locais alinhadas às boas práticas ambientais. A postergação de decisões que efetivamente venham a inserir o componente ambiental na gestão local torna as soluções cada vez mais caras e difíceis, inclusive comprometendo as outras dimensões do desenvolvimento local, ou seja, a área de saúde pública, a economia local, o saneamento, entre outros.

A inexistência de um sistema de gestão ambiental municipal, segundo Little (2003), “deixa o Município à mercê dos órgãos ambientais das esferas federal e estadual que, a rigor, não possuem estrutura suficiente para atender às demandas locais nem para perceber as especificidades de cada Município". Ocorre que no Brasil a política ambiental ainda hoje permanece em segundo plano na política de desenvolvimento local, conforme evidenciam os dados apresentados neste artigo; isso fragiliza as es- 
truturas do sistema de gestão ambiental local e dificulta, portanto, o próprio alavancamento do sistema de meio ambiente, em um círculo vicioso prejudicial ao desenvolvimento da municipalidade.

Dentro deste enfoque, este artigo visa caracterizar e contextualizar o Sistema Municipal de Meio Ambiente no Brasil, discutindo o seu papel estratégico na governança para a sustentabilidade municipal, entendida como processo de articulação e negociação que potencializa a integração do componente ambiental no processo de tomada de decisão local e, consequentemente, no processo de desenvolvimento local.

\section{Caracterização}

O Sistema Municipal de Meio Ambiente, SISMUMA, estrutura integrante do Sistema Nacional e Estadual de Meio Ambiente, SISNAMA e SISEMA, respectivamente, é o conjunto de órgãos e entidades do Município que são responsáveis pela preservação, conservação, proteção, defesa, melhoria, recuperação e controle do meio ambiente e uso adequado dos recursos ambientais do Município. A instituição do SISNAMA pela Política Nacional de Meio Ambiente - PNMA - alinhou o Brasil entre os primeiros países que elaboraram e implementaram um sistema integrado de gestão do meio ambiente, que envolveu todo o seu contexto federativo (União, Estado e Município) para que se tivesse supletividade dos níveis de poder, do nacional ao local, com foco na melhoria da qualidade ambiental. Outro aspecto inovador à época da aprovação da PNMA foi a criação de conselhos participativos consultivos e deliberativos em cada uma das esferas, potencializando um processo de democracia representativa, bastante incipiente à época, especialmente considerando o momento de transição de um regime ditatorial para um regime democrático.

O Município, além da decisão política de envolverse no tema e enfrentar todos os conflitos oriundos da tomada de posição em relação a um tema tão abrangente e complexo como o ambiental, também precisa preparar-se, capacitar-se. Isso envolve a instituição de um Sistema Municipal de Meio Ambiente, com a criação de normas e órgãos ambientais municipais, como um Conselho e um Fundo Municipal de Meio
Ambiente; além disso, é preciso a disponibilização dos recursos necessários, legais, estruturais, operacionais, financeiros, tecnológicos e técnicos, de modo a atender tanto às exigências de uma ação eficiente no trato das questões ambientais, quanto as suas interfaces com as outras políticas municipais. A Figura 1 apresenta uma representação gráfica dos diversos componentes que estruturam o SISMUMA. Tudo o que tem relação com o desenvolvimento com qualidade ambiental deve ser levado em conta, inclusive a atuação do mercado.

Para operacionalizar o Sistema Municipal de Meio Ambiente, o Município dispõe de diversos instrumentos adequados à obtenção de um desenvolvimento com sustentabilidade. Os instrumentos são recursos no sentido de atingir os objetivos propostos. Os diversos instrumentos devem contemplar as bases de uma política ambiental local e compreendem: instrumentos de comando e controle, econômicos, participativos, de informação e educação, de planejamento e de fortalecimento institucional. O próprio Fundo Municipal de Meio Ambiente também pode ser considerado um instrumento. É importante trabalhar na inserção do componente ambiental nos diversos instrumentos de planeja-

\section{Figura I - Representação esquemática do SISMUMA}

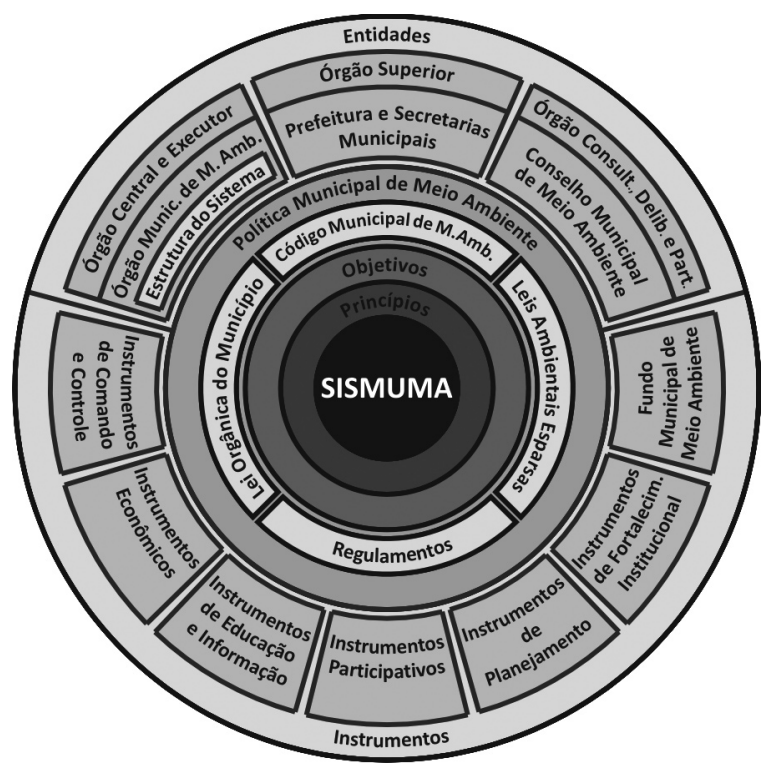


mento do Município, como o Plano Plurianual, Plano Diretor, Zoneamento Ambiental, Código de Posturas, Lei de Parcelamento, Uso e Ocupação do Solo, entre outros. Ademais, é fundamental a operacionalização da política ambiental no âmbito do planejamento orçamentário, em especial, a Lei de Diretrizes Orçamentárias, Lei de Orçamento Anual e no plano de desenvolvimento sustentável, por exemplo, por meio da Agenda 21 Local.

A implementação do SISMUMA é mais eficaz se for compreendido seu aspecto dinâmico, no sentido de ampliação gradual de atores, responsabilidades e instrumentos. A operacionalização de um Sistema Municipal de Informações sobre Meio Ambiente adequado, como base de dados para o planejamento estratégico, potencializa a gestão ambiental local. Assim, ao favorecer a integração dos componentes do desenvolvimento sustentável no processo de tomada de decisão, reforça-se a capacidade de governança ambiental e consolida-se o SISMUMA como peça fundamental na construção do desenvolvimento local. É esta ampliação do entendimento do SISMUMA que efetivamente torna os resultados mais concretos e efetivos, ao mesmo tempo em que exige do sistema alinhamento com princípios de equidade, transparência, participação e comprometimento.

\section{A Decisão Política de Envolver-se no Tema}

A ação política de envolver-se no tema demanda apoio político e social por meio de relações e ações institucionais, envolvendo diretamente o Gabinete do Prefeito, as diversas Secretarias e Órgãos Municipais, a Câmara Municipal, os juízes, promotores, delegados e lideranças ambientais e da sociedade civil. É indispensável possuir a compreensão, o envolvimento e o comprometimento por parte daqueles que detêm o poder de decisão com a defesa do meio ambiente.

Estes envolvidos são coresponsáveis pela definição das estratégias, pelo estabelecimento dos objetivos, diretrizes e prioridades, dos planos e programas de governo, dentro de um processo em que a participação dos órgãos públicos deve ser dinâmica e integrada, em que cada etapa de execução de projetos ou programas atribui aos atores envolvidos papéis distintos (Cepam 1992). Entre os desafios destaca-se a necessidade de integração vertical e horizontal das secretarias, departamentos e seções da prefeitura, em formato colaborativo. Também é essencial a integração das instituições municipais com as instâncias regionais, estaduais e federais, em formato de apoio, favorecendo um melhor uso dos recursos públicos e privados para a promoção da qualidade ambiental e saúde pública. Por fim, é extremamente necessária a elaboração de um programa de sensibilização sobre a questão ambiental na administração pública, como um primeiro passo para a conscientização a respeito da seriedade com que deve ser tratada a questão ambiental (Philippi Jr e Malheiros, 2007; Cezare e col., 2007).

Deve-se reconhecer a interação entre as questões ambientais e as diversas políticas públicas urbanas e rurais e, desta forma, avançar na introdução da variável ambiental nos sistemas locais de planejamento e na execução de políticas de desenvolvimento do Município, construindo mecanismos que levem à sustentabilidade, o que pode ser feito no contexto do Sistema Municipal de Meio Ambiente. É essencial que a dimensão ambiental, dada sua complexidade, permeie os diversos setores da administração municipal, evitando uma visão fragmentada e setorizada do assunto. Além disto, para se ampliar a eficácia de políticas, especialmente no contexto da sustentabilidade, esforços devem ser direcionados à capacitação institucional voltada ao fortalecimento da avaliação e abordagem de questões cruciais, como aquelas relacionadas a escolhas entre políticas alternativas, e a modalidades de implementação entre as opções de desenvolvimento, baseadas no entendimento das potencialidades e limitações do meio ambiente.

Neste formato, é certo que os órgãos do SISMUMA passam a ter peso na própria administração da municipalidade, articulando-se com o restante da administração municipal no sentido de encaminhar políticas, planos, programas e projetos municipais voltados à sustentabilidade. E "independente da condição política dos Prefeitos e Vereadores, a variável ambiental necessita de uma abordagem permanente, não devendo ser confundida com uma proposta passageira ou vinculada ao momento político da prefeitura" (Famurs, 2005). Apesar de decorridos mais de 25 anos da PNMA, observa-se ainda que entre 
as dificuldades do processo de planejamento local estão a adequação dos instrumentos à estrutura de gestão, a falta de integração entre eles e a falta de qualificação profissional do corpo técnico.

A falta de reconhecimento da importância das políticas ambientais pela sociedade e pelos governantes - que por vezes consideram os cuidados ambientais como um inimigo do desenvolvimento e insistem em considerar a sustentabilidade como assunto de preocupação futura, como se a priorização de outros problemas automaticamente excluísse essa preocupação - cria um grave problema. Por vezes, a preocupação com a fuga de investimentos em Municípios que possuem regulamentos ambientais mais rigorosos implica em um afrouxamento do SISMUMA. A política de proteção ao meio ambiente só terá efeito com a ação persistente e conjunta dos vários atores - órgãos públicos, entidades não governamentais e população e certamente o entendimento de que as questões ambiental e econômica são complementares, e não díspares.

\section{A Implantação do SISMUMA}

A definição do modelo de Sistema Municipal de Meio Ambiente a ser adotado - e consequentemente das prioridades ambientais - depende das características de cada municipalidade e do contexto regional no qual o Município está inserido. Segundo Cepam (2007), "as características peculiares de cada Município criam situações diferenciadas no processo de desenvolvimento e delineiam uma tipologia ambiental estruturada em seu contexto territorial, social, econômico e cultural". Neste sentido, e observando o aspecto difuso da questão ambiental que extrapola os limites do município, alguns pressupostos devem ser obrigatoriamente colocados na política e ética, que atendam de fato às necessidades democráticas da sociedade civil.

Philippi Jr e colaboradores (2004a) lembram que os Municípios, ao iniciarem a construção do SISMUMA, "devem ampliar incessantemente a compreensão da realidade local, no sentido de apreendê-la na sua totalidade, reunindo uma ordem determinada de conhecimentos em um número reduzido de princípios, que servirão de fundamentos para as práticas de interesse ambiental". Deve-se optar por um formato e posição institucional que possa ter força e exequibilidade dentro das condições do Município, evitando sobreposições e conflitos, para maximizar o número de ações que possam ser efetuadas, e buscando soluções criativas com viabilidade econômica, para se alcançar o patamar desejável em um processo de desenvolvimento real e sustentável.

A instalação de um Sistema Municipal de Meio Ambiente é realizada gradativamente, "apoiada em etapas vencidas com sucesso, as quais fornecem o respaldo necessário à sua progressiva implantação", pois a capacidade de atuar para o bem comum é um processo que exige capacitação e amadurecimento do poder público e da sociedade (Anamma, 1999). Procedimentos e mecanismos longos e burocratizados serão progressivamente substituídos por caminhos ágeis e eficazes, que evitem a ideia de ser o setor ambiental um protelador de decisões e um freio ao desenvolvimento. A administração municipal concentrará esforços no sentido de aprimorar as atividades fins, ou seja, aquelas que repercutem em significativos ganhos na qualidade de vida das pessoas.

São inúmeras as dificuldades que os Municípios encontram na implantação e manutenção de seu Sistema Municipal de Meio Ambiente, porém é extremamente necessário avançar-se na sua consolidação. A crise financeira e a grande dimensão territorial dos Estados e da União reforçam a necessidade de o Município capacitar-se para assumir o seu dever de preservar o meio ambiente. Ainda se observa que, apesar do crescente número de municípios que implementaram seus SISMUMAs, muitos Órgãos Municipais de Meio Ambiente não possuem a estrutura que seria necessária, os Conselhos Municipais de Meio Ambiente não funcionam como seria o desejável e é necessário, na maioria das vezes, a complementação das estruturas legais.

\section{A Política Municipal de Meio Ambiente}

Boa parte da legislação ambiental estadual e federal é aplicável na esfera municipal, mas os Municípios brasileiros também podem criar sua própria legislação ambiental, com fundamento nos artigos 30, 
I, da Constituição Federal, e 181, da Constituição do Estado de São Paulo. Podem assim fazê-lo para suplementar as legislações estadual e federal e para atender ao interesse local, refletindo nestas os princípios e as metas ambientais determinadas pelos governantes. De acordo com Mazollenis (1998), "uma política de meio ambiente constitui-se no conjunto de práticas, normas e estratégias, produto das interações entre o poder público e a população, que visem à elevação permanente da qualidade de vida desta e das futuras gerações", mediante a proteção, preservação, conservação, controle e recuperação do meio ambiente.

A Política Municipal de Meio Ambiente é um importante instrumento de fortalecimento institucional do SISMUMA, e tem como premissa básica a formulação de políticas condizentes e específicas para cada Município. Segundo Cepam (1992), "a proposta de uma política municipal de meio ambiente deve basear-se em ampla análise das potencialidades dos recursos locais e considerar a situação da administração pública e os problemas vividos pelo Município, as aspirações da população e, principalmente, trazer uma visão abrangente de como tratar o desenvolvimento local por caminhos socialmente mais justos e mais humanos" para que "sejam identificados os objetivos das políticas públicas, as tendências do desenvolvimento, os problemas relevantes e os critérios a serem empregados na administração dos conflitos”. Nesta linha, Dowbor (1993) apud Cepam (2007) salienta que as políticas municipais que dão certo não são as políticas que querem resolver tudo em nível local, mas aquelas que fazem convergir os seus esforços sobre o que o nível local realmente permite. Compreender bem o Município implica saber hierarquizar corretamente os diversos tipos de decisão.

Os Municípios podem estabelecer suas políticas municipais de meio ambiente através de distintos formatos. De acordo com o IBGE (2005), em 2002, as disposições relativas ao meio ambiente no âmbito municipal integraram tanto a sua Lei Orgânica, presente em $81 \%$ das municipalidades, como o seu Plano Diretor (13\%), assim como podem ser tratadas por meio de normas e planos setoriais (7\%) ou até mesmo podem constituir um conjunto de leis esparsas, tal como ocorre nas esferas estadual e federal (43\% dos Municípios possuíam pelo menos um tipo de norma ambiental). Estas informações, segundo o tamanho da população dos Municípios, são apresentadas na Figura 2.

Figura 2 - Proporção (\%) de municípios segundo classes de tamanho da população e tipo de legislação ambiental dentre os que informaram a existência de legislação ambiental - 2002

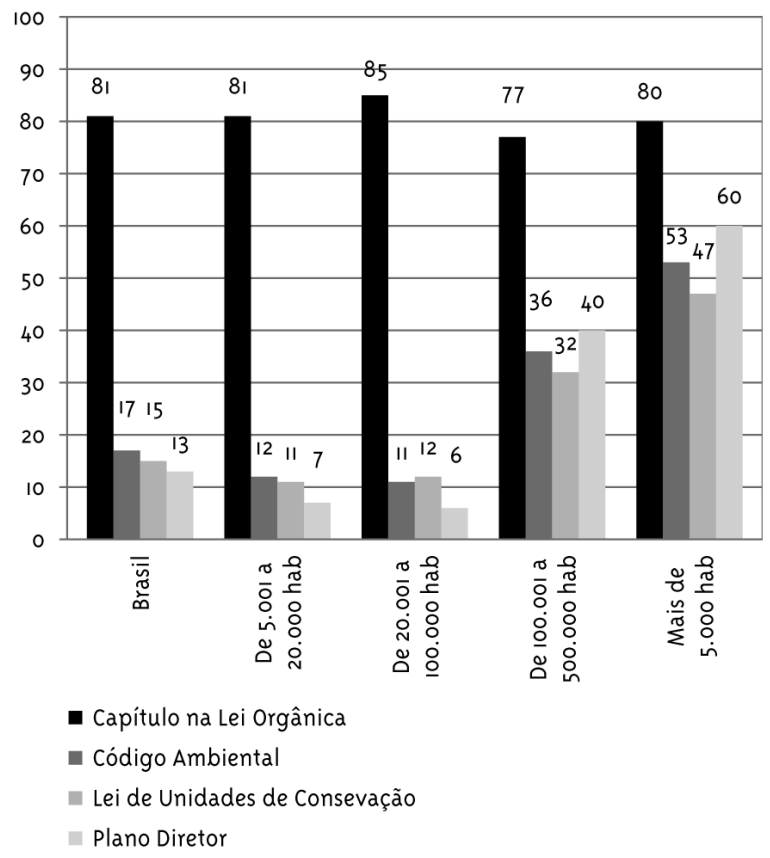

Em 17\% dos Municípios, a legislação ambiental é consolidada no Código Municipal de Meio Ambiente (CMMA), uma lei importantíssima que regula a ação do poder público municipal e sua relação com os cidadãos e instituições públicas e privadas na preservação, conservação, defesa, melhoria, recuperação e controle do meio ambiente. Por meio desta Lei cria-se o Sistema Municipal de Meio Ambiente, contendo as definições do que vai ser considerado, definindo os atores, os procedimentos administrativos e legais, os responsáveis pelo cumprimento da

\footnotetext{
2 DOWBOR, L. O município e o meio ambiente. In: BURSZTYN, M. (Org.). Para pensar o desenvolvimento sustentável. São Paulo: Brasiliense;Ibama;Inape, 1993.
} 
estrutura administrativa, das normas de qualidade e dos padrões de emissão que serão permitidos, e do nível de delegação de responsabilidades e decisões a serem outorgadas, principalmente ao Conselho Municipal de Meio Ambiente. O CMMA pode ainda prever a origem dos recursos financeiros e orientar a sua aplicação. Entenda-se por "procedimentos administrativos e legais", os seus instrumentos, que são os meios pelos quais se implementa a política local de meio ambiente, e podem ser tanto corretivos como preventivos.

Ressalta-se que a estruturação de uma Política Municipal de Meio Ambiente não passa apenas pela criação de novas normas ambientais, mas também pela necessidade de atualizar a sua Lei Orgânica e efetuar uma revisão das políticas urbanas adotadas até então, explicitadas através do Plano Diretor, da Lei de Uso e Ocupação do Solo, do Código de Obras, de Postura, Tributário, Sanitário, sob o prisma da sustentabilidade, compatibilizando-os com o Código Municipal de Meio Ambiente e as demais normas ambientais locais. São diversos os instrumentos de gestão ambiental que servem como guia de planejamento e precisam ser utilizados na sua plenitude. A definição de planos, programas e projetos também são fundamentais para o planejamento das ações.

Naturalmente, nem toda legislação ossui condições de cumprir com suas funções pela sua simples exigência. Souza e colaboradores (2003) salienta que "a maior parte dos Municípios brasileiros ainda não conseguiu implementar uma política ambiental que, ao mesmo tempo em que responda às necessidades locais, seja coerente e compatível com as políticas estabelecidas nas instâncias superiores de governo". Pesquisa realizada por Philippi Jr e colaboradores (2004b) em alguns Municípios baianos identificou que entre as dificuldades para que o Município atenda à legislação estão a falta de recursos humanos e materiais, a pouca informação e orientação para os funcionários, e a estrutura administrativa não adequada.

Este mesmo estudo elencou ainda as principais dificuldades na implantação da PMMA, entre as quais pode-se citar a inexistência, insuficiência e desatualização de estrutura legal ambiental municipal (como código municipal de meio ambiente, plano de gestão ambiental, plano diretor, política de educação ambiental, código de obras), a demora e a falta de aplicação da legislação, a ausência de transparência e de atribuições de responsabilidades na aplicação de normas ambientais e a falta de implementação da Agenda 21 Local, existindo apenas como um documento, sem participação comunitária nas decisões municipais

É importante ressaltar que se faz necessária a participação da população na formulação das políticas públicas ambientais, visto que atualmente não se concebe qualquer forma de gestão que não considere o planejamento participativo como integrante desse processo, conforme estabelece o Estatuto da Cidade. A efetividade de qualquer política ambiental depende muito mais das condições da qualidade política da população: o Estado detém papel fundamental, embora instrumentador, não de condução e definição, mas de coordenação, normatização e apoio.

Portanto, faz-se necessário que as municipalidades adotem políticas ambientais claras e definidas, compatíveis com as políticas ambientais das demais esferas de governo e com os recursos disponibilizados, para que a política ambiental saia do papel. "Outro desafio é romper a separação artificial entre elaborar uma lei, regulamentá-la e o processo de gestão. A elaboração e regulamentação de uma norma ou política não deve se esgotar no contexto legal, mas deve ser, ao mesmo tempo, o processo de gestão desta norma ou política" (Mazzolenis, 1998).

\section{Os Órgãos Municipais de Meio Ambiente}

Para tornar efetivas as decisões políticas referentes ao meio ambiente, assim como para fazer serem aplicadas e respeitadas as leis, é fundamental a construção de uma estrutura que efetue a gestão do meio ambiente no âmbito municipal, e o Órgão Municipal de Meio Ambiente, OMMA, é a peça fundamental deste sistema. São atribuições do OMMA planejar, promover, coordenar, fiscalizar e executar a política municipal de meio ambiente, conjuntamente com os demais órgãos do Município, objetivando criar condições para o desenvolvimento sustentável do Município. Cabe ainda ao OMMA fornecer o suporte técnico ao Conselho Municipal de Meio Ambiente e submeter à sua deliberação as propostas 
de normatização, procedimentos e diretrizes para o gerenciamento ambiental municipal, assim como os pareceres técnicos que subsidiarão o licenciamento de atividades potencialmente degradadoras do meio ambiente de impacto local. A implementação dos OMMA é uma realidade no Brasil, conforme pesquisa do IBGE revela: em 2008 existiam 4.327 $(77,8 \%)$ Municípios com algum tipo de estrutura na área ambiental (IBGE, 2008).

Os Órgãos Municipais de Meio Ambiente podem se adequar a diversos modelos organizacionais, tais como órgãos típicos da administração direta (secretarias, departamentos e assessorias) ou como órgãos da administração indireta (autarquias, fundações, agências e empresas), os quais mantêm vínculos administrativos com o poder executivo municipal, conservando significativa autonomia. Estes órgãos são os responsáveis pela centralização das atividades de gestão ambiental e pela execução de programas, projetos e pelo controle e fiscalização de atividades potencialmente degradadoras da qualidade ambiental. Os OMMA se estruturam das mais diversas formas. Segundo o IBGE (2008), em 2008 apenas cerca de $16,3 \%$ das municipalidades possuíam secretarias encarregadas exclusivamente de meio ambiente, enquanto $54,8 \%$ tratavam a questão em secretarias conjuntas com outras áreas; e, ainda, $28,9 \%$ instituíam a questão ambiental no interior de organizações pré-existentes, unidades administrativas subordinadas e/ou associadas a outras secretarias, departamentos ou órgão similar. Estas informações, segundo o tamanho da população dos Municípios, são apresentadas na Figura 3, em que se observa que quanto maior o município, em termos de população, maior a presença do OMMA.

O efetivo exercício das ações do OMMA pressupõe a disponibilização de recursos -estruturais, operacionais, financeiros, tecnológicos e técnicos - para que possa exercer o seu papel de executor da política ambiental municipal, criando reais condições de fortalecimento institucional. Ressalta-se que todos estes recursos devem possuir um custo de funcionamento compatível com as condições econômicas municipais. Entre os principais empecilhos ao funcionamento do OMMA estão a sua ausência, falta de fortalecimento, desestruturação, omissão, conivência e falta de autonomia, conforme
Figura 3 - Proporção de Municípios, segundo classes do tamanho da população dos municípios e grandes regiões, por tipo de órgãos Municipais de Meio Ambiente - 2008

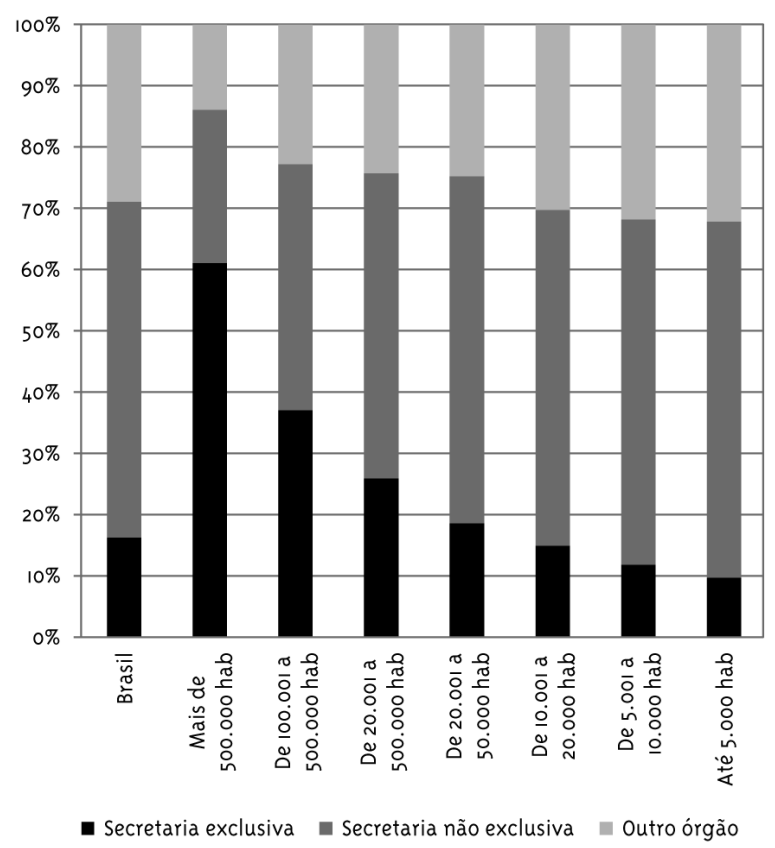

evidenciou Philippi Jr e colaboradores (2004b) em um estudo em alguns Municípios baianos.

É importante que o OMMA se organize tecnicamente e tenha metodologias definidas para ações, sejam elas específicas, ou através de consórcios municipais ou através convênios de assistência técnica com outras áreas da administração pública, universidades e instituições de pesquisa. A implantação de uma unidade de meio ambiente em nível municipal deve considerar vários aspectos, como a sua área, população, as características dos principais problemas ambientais e a vocação da municipalidade, para só assim definir os seus quadros de servidores, a sua estrutura e as suas formas de atuação.

A capacitação operacional é outro fator fundamental para o sistema enquanto agente das ações executivas, já que falhas no sistema, como a falta de articulação e integração com outras áreas do governo, conflitos e falta de cooperação com outras esferas de poder e ausência de um planejamento estratégico e de outras práticas modernas no interior da administração pública comprometem todo o 
esforço alocado nas capacidades técnica e tecnológica. $\mathrm{O}$ aparelhamento operacional é indispensável e deve-se ter disponível um espaço físico definido, veículos para locomoção dos técnicos, equipamentos de informática, comunicação e monitoramento, softwares de informação geográfica e suporte administrativo, entre outros. É muito interessante também efetuar a implantação de um sistema de informações ambientais, local ou regional, de modo a subsidiar a tomada de decisões e o estabelecimento de políticas públicas.

É essencial ao OMMA possuir recursos humanos devidamente habilitados, com visão sistêmica e capacidade analítica e reflexiva suficientes para interpretar os problemas e encaminhar soluções de caráter técnico e administrativo adequadas à situação estudada. No entanto, infelizmente, pesquisa do IBGE (2008) de 2008 demonstrou que os recursos humanos dos OMMAs são extremamente reduzidos e necessitam de melhor capacitação e treinamento. A proporção média dos servidores de meio ambiente no quadro de pessoal dos Municípios é de apenas o, $8 \%$, sendo que $48,9 \%$ são estatutários, $20,3 \%$, comissionados, 13,2\%, com vínculo permanente, $11,6 \%$ celetistas e 6\%, estagiários (IBGE, 2008).

Na maior parte dos Municípios, os funcionários sem vínculo são, em média, mais numerosos que os com vínculo empregatício. Devido ao fato de muitos cargos de confiança serem preenchidos com técnicos que ficam durante apenas uma administração, criase uma alta rotatividade de funcionários. Outros entraves à implantação do SISMUMA, por parte dos gestores ambientais, são a existência de conflito entre interesses políticos, pouco compromisso com a integração dos poderes e a falta de vontade política, de prioridade e de ações de educação ambiental, conforme levantaram Philippi Jr e colaboradores (2004b).

\section{O Conselho Municipal de Meio Ambiente}

O Conselho Municipal de Meio Ambiente, COMUMA, é o órgão superior do SISMUMA, de caráter normativo, deliberativo ou consultivo e fiscalizador das questões afetas ao meio ambiente no âmbito local. Esse espaço destina-se a colocar em torno da mesma mesa representantes da administração municipal, do legislativo, da administração estadual, do ministério público, da sociedade civil organizada e entidades da indústria, do comércio, de serviços, da agricultura, universidade, instituições de pesquisa (moradores, trabalhadores, religiosas, movimentos sociais, ambientalistas, defesa do consumidor, classe entre outras) no debate e na busca de soluções para o uso dos recursos naturais e para a recuperação dos danos ambientais. Os COMUMAs não possuem a função de criar leis, atribuição esta da Câmara Municipal, mas podem sugerir a criação de leis e realizar a regulamentação das já existentes, por meio de resoluções. Podem e devem estabelecer normas ambientais, como procedimentos de monitoramento dos recursos naturais, de licenciamento local, etc.

Trata-se de um instrumento de exercício da democracia, educação para a cidadania e de convívio entre setores da sociedade com interesses diferentes. Segundo Carvalho e colaboradores (2005), o COMUMA é um espaço de participação social, negociação de demandas e interesses e mediação de conflitos, complementar às formas clássicas de representação indireta, via partidos políticos e representação legislativa, que "ao mesmo tempo em que estabelece um novo formato de relação $\varepsilon_{s}$ tado e sociedade, institucionaliza a participação e possibilita a entrada em vigor de uma nova cultura cívica". O COMUMA é um dos mais importantes instrumentos de participação de apoio à política ambiental local, promovendo novas relações entre Estado e sociedade para o tratamento das questões ambientais.

A participação da sociedade local nestes Conselhos permite aos cidadãos tomar parte ativa no processo de decisão e pressiona o poder local a assumir a sua responsabilidade frente ao meio ambiente, dando legitimidade ao processo. Segundo Brasil (2005), por meio da participação cidadã nos espaços institucionais, é possível reverter o padrão de planejamento e execução das políticas públicas, ao provocar um tensionamento nas agências estatais, tornando-as mais transparentes, mais responsáveis e mais suscetíveis ao controle da sociedade. Salienta-se que as decisões sem a participação e o conhecimento da comunidade apresentam maior risco de falhas e certamente os custos associados às decisões sempre são divididos por toda a comunidade. 
De acordo com Brasil (2005), "esses mecanismos de participação obrigariam o Estado a negociar suas propostas com outros grupos sociais, dificultando a atual confusão entre interesse público e interesses de grupos que circulam em volta do poder estatal e costumam exercer influência direta sobre ele". 0 COMUMA estabelece uma instância de articulação que proporciona uma oportunidade para a troca de informações entre os stakeholders, a participação da comunidade para contrabalancear a dominância de outros grupos organizados, que nem sempre têm interesse maior no coletivo, e favorece a coordenação entre diversos atores na solução dos problemas ambientais e na promoção da sustentabilidade. Portanto, o COMUMA pode tornar-se um dos grandes pilares da administração do município, junto com o executivo local, ou seja, a Prefeitura, suas secretarias e órgãos, na definição de políticas, planos, programas e projetos que atendam às demandas da sociedade.

A composição e competências do COMUMA devem ser definidas em lei ou decreto de acordo com a realidade local. Salienta-se que a regulamentação dos Conselhos e as definições quanto ao seu papel deliberativo ou consultivo, atribuições, composição, regras de funcionamento e existência ou não de fundos circunscrevem limites e possibilidades ao seu funcionamento. Por exemplo, sem decidir sobre a alocação de recursos, o Conselho assume uma função mais técnica e afasta-se da participação dos movimentos populares. De forma a potencializar no seu todo a proposta deste espaço de participação, o Conselho Municipal de Meio Ambiente deve ser representativo e reunir representantes legítimos de todos os segmentos da sociedade local interessados, espelhando em sua composição as forças atuantes no local. Para isso, é recomendável a paridade entre a administração municipal e os demais membros.

Também é essencial que o COMUMA possua função deliberativa, descentralizando, desta forma, a administração pública municipal. Segundo a Anamma (1999, p. 49), "o caráter consultivo e deliberativo do Conselho amplia as possibilidades de serem melhor canalizados os anseios da sociedade e cria condições propícias para o estabelecimento de parcerias, baseadas em participação efetiva nas decisões e na confiança adquirida com a aplicação das decisões tomadas de forma conjunta e democrática". O Conselho Municipal de Meio Ambiente pode assumir diversos tipos de funções, tais como debate de problemas públicos, proposição de soluções, tomada de decisão, assessoria e acompanhamento de processos decisórios e de ações governamentais. Ele pode se tornar o responsável pela aprovação e acompanhamento da Política Municipal de Meio Ambiente, bem como dos demais planos ligados à área, como o Plano Diretor, o Zoneamento Ambiental e a Agenda 21 Local.

É importante não deixar de mencionar a existência de motivação de ordem econômica para que os Municípios criem os seus Conselhos de Meio Ambiente, pois para gozar das prerrogativas de expedir licenças ambientais, previstas na Resolução Conama $\mathrm{n}^{\circ}$ 237/97, devem possuir seus Conselhos de Meio Ambiente "com caráter deliberativo e participação social e, ainda, possuir em seus quadros, ou à sua disposição, profissionais legalmente habilitados".

Os Conselhos Municipais começaram a se organizar em 1975, iniciando-se pelo Município de Cubatão, SP (IBGE, 2008). Segundo o levantamento do IBGE, em $2008,47,6 \%$ das municipalidades possuíam COMUMAs, embora apenas 33,8\% dispusessem de um Conselho ativo (que tenha se reunido pelo menos uma vez nos últimos doze meses). Os Conselhos são predominantemente deliberativos $(74,4 \%)$ e/ou consultivos (71,8\%), 40,5\% possuem caráter fiscalizador, 35,6\%, caráter normativo e 71,6\% possuíam representação social igual ou maior a 50\%; apenas 5,5\% dos Municípios apresentam Conselhos com todas estas características e que ainda são considerados ativos (IBGE, 2008) - vide Figura 4.

No quadro geral dos conselhos participativos, é baixa a presença de Conselhos Municipais de Meio Ambiente, que ocupam o $6^{\circ}$ lugar, após os Conselhos da Saúde, Assistência Social, Educação, Crianças e Adolescentes, e Emprego e Trabalho (IBGE, 2003). Importante salientar que o IBGE (2008) notou que o crescimento dos COMUMAS tem ocorrido de maneira mais evidente nos anos imediatamente seguintes aos das eleições municipais (1997, 2001 e 2005).

O Conselho de Meio Ambiente, onde existe formalmente, funciona de maneira diferenciada, dependendo do grau de democratização alcançado pelos grupos que o compõem no Município. O fun- 
Figura 4 - Percentual de municípios com Conselho Municipal de Meio Ambiente e suas características (\% em relação ao total de municípios com Conselho de Meio Ambiente)

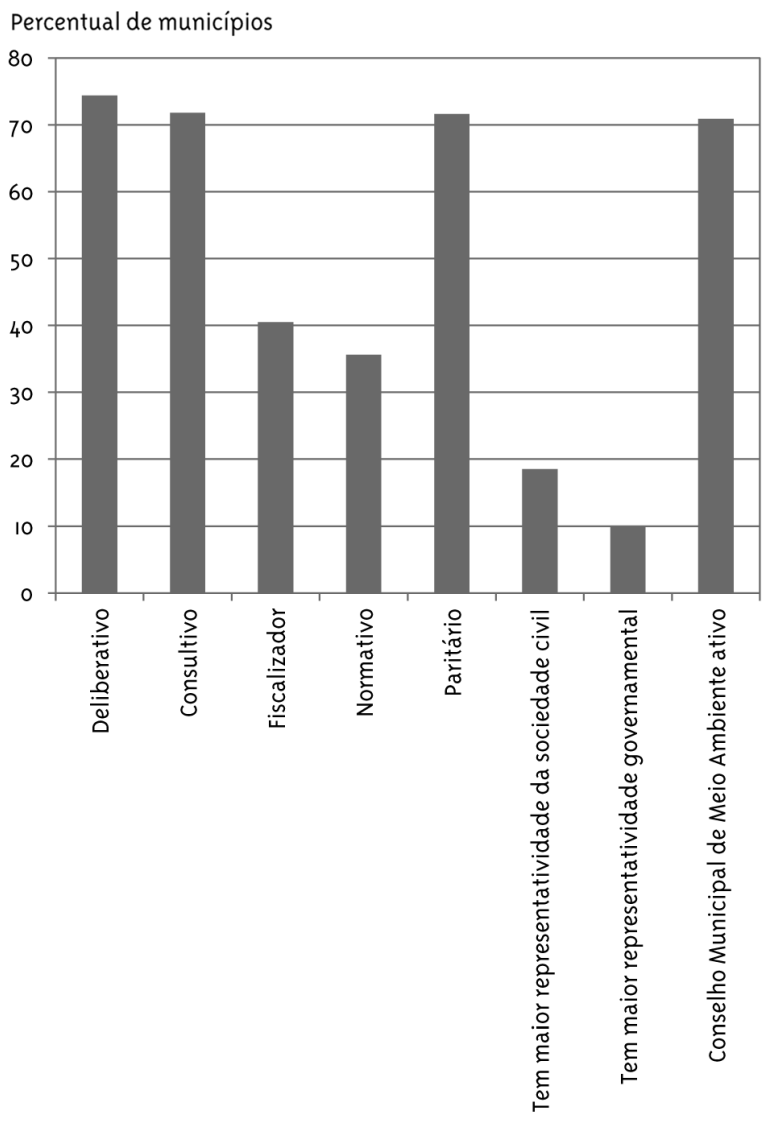

cionamento do COMUMA e a qualidade de seus processos participativos dependem não só dos arranjos estabelecidos pelo poder público, mas também da disposição e da capacidade dos atores da sociedade civil em participar e negociar. Ressalta-se que as recomendações do Conselho ou deliberações aí tomadas dependerão, eventualmente, para serem efetivadas, tanto do peso político que a entidade possui na administração local, quanto de recursos nem sempre disponíveis nas municipalidades. Entre as principais dificuldades que os COMUMAs enfrentam estão: falta de fortalecimento, inoperância, manipulação, desarticulação, falta de legitimidade, ausência de funcionalidade, legitimidade das representações, criação apenas com o intuito de angariar recursos, conflito de interesses entre o setor público e privado, função estritamente consultiva e falta de participação popular (Philippi Jr e col., 2004b).

Pesquisa realizada em 1997 pela Secretaria de Estado de Meio Ambiente de São Paulo (SMA, 1998 3 apud Anamma, 1999) revelou que a criação do COMUMA está intimamente ligada ao processo de envolvimento da sociedade local e a participação desta nos Conselhos está condicionada à dimensão da problemática ambiental na área e tende a aumentar de acordo com a densidade populacional do Município. Ambas as pesquisas sobre os COMUMAS, a nacional do IBGE (IBGE, 2008) e a paulista da SMA evidenciam que os Conselhos de Meio Ambiente são mais frequentes em Municípios mais populosos. $\mathrm{O}$ IBGE (2005a) identificou ainda que nos $22,2 \%$ das municipalidades brasileiras que possuem Conselho vivem quase a metade dos brasileiros $(47,6 \%)$.

Por fim, salienta-se, conforme lembra Mazzolenis (1998), que existe a falsa ideia de que a mera criação de conselhos garante a participação, mas a criação dos conselhos pode estar relacionada à mera necessidade do Executivo Municipal em referendar suas ações ou em resposta a iniciativas da população. Segundo este autor, "as demandas de certos grupos sociais [...] podem ter dificuldades de chegar às esferas de discussão e decisão" e pode ocorrer "o dilema da representação, onde os interesses dos diversos segmentos da população não se vejam contemplados" e "o funcionamento, muitas vezes, pode tornar-se burocrático, baseado em procedimentos administrativos".

\section{O Fundo Municipal de Meio Ambiente}

O Fundo Municipal de Meio Ambiental, FMMA, é o órgão responsável pela captação e pelo gerenciamento dos recursos financeiros alocados para o meio ambiente no Município. O FMMA tem como objetivo financiar as seguintes atividades: planos, programas, projetos e ações de iniciativas públicas e privadas, uso racional e sustentável dos recursos naturais, controle, fiscalização, defesa e recuperação

3 SMA - Secretaria do Meio Ambiente do Estado de São Paulo. Aspectos ambientais urbanos dos municípios do Estado de São Paulo: relatório de pesquisa. São Paulo: SMA, 1998. 
do meio ambiente e a educação ambiental. O FMMA constitui-se em um incentivo para a implementação de uma estrutura ambiental local e traz à área ambiental a possibilidade de estabelecer estratégias de ação para tratar a questão ambiental em nível local de maneira autônoma.

O FMMA deve ser criado e operado por legislação específica, de forma a permitir melhor gerenciamento da arrecadação obtida com a aplicação da legislação ambiental, tais como dotação orçamentária específica, valores arrecadados através de instrumentos econômicos, de multas aplicadas, da cobrança de taxas pelo licenciamento ambiental e saldos resultantes de contribuições, convênios e doações, ou proveniente de contratos com instituições e fundos, sejam privados, estaduais, federais e internacionais, e de outros recursos que, pela sua natureza, possam ser destinados a esse fim. Este fundo deve ser vinculado ao órgão ambiental municipal, gerido e administrado pelo órgão municipal competente, e o Conselho Municipal de Meio Ambiente deverá fiscalizar, assessorar e indicar as prioridades para a aplicação de seus dos recursos, se lhe for atribuída essa responsabilidade na sua lei de criação, o que é fundamental, no sentido de efetivamente dar força ao Conselho.

Com a sanção da Lei de Crimes Ambientais (Lei Ordinária 9.605) (Brasil, 1998), a sociedade brasileira, os órgãos ambientais e o Ministério Público passaram a contar com um instrumento que lhes garante agilidade e eficácia na punição dos infratores do meio ambiente. Foi através desta lei que o FMMA pôde carrear para a área ambiental do Município recursos que, de modo contrário, seriam repassados ao Fundo Nacional de Meio Ambiente.

A Lei de Crimes Ambientais, ao definir a infração administrativa ambiental como "toda ação ou omissão que viole as regras jurídicas de uso, gozo, promoção, proteção e recuperação do meio ambiente" (art. 70), estabeleceu que "são autoridades competentes para lavrar auto de infração ambiental e instaurar processo administrativo os funcionários de órgãos ambientais integrantes do Sistema Nacional de Meio Ambiente" (art. 70, §1), e que "os valores arrecadados em pagamento de multas por infração ambiental serão revertidos ao Fundo Nacional do Meio Ambiente, Fundo Naval, fundos estaduais ou municipais de meio ambiente, ou correlatos, conforme dispuser o órgão arrecadador" (art. 73). Através da legitimação dos Fundos Municipais de Meio Ambiente, os Municípios passaram a contar com um suporte significativo para obterem recursos ao SISMUMA.

Os Fundos Municipais de Meio Ambiente ainda são pouco frequentes no país: em 2008, apenas 22,5\% dos Municípios o possuíam e, destes, só $36,6 \%$ podiam ser considerados ativos, ou seja, que financiaram algum projeto no último ano (IBGE, 2008). Porém, a relevância dos FMMA é grande quando menos da metade dos municípios não possui recursos específicos para o meio ambiente (IBGE, 2008) e quando quatro em cada cinco municípios brasileiros não têm receita suficiente para prestar serviços públicos de qualidade (levantamento do Instituto Brasileiro de Administração Municipal citado por O Estado de S. Paulo, 2007). Observa-se que existem diversas fontes que podem abastecer o caixa do FMMA, conforme elenca Tatagiba e Leme (2008): dotação orçamentária, orçamento de outras secretarias e entes do governo; multas administrativas e sanções judiciais; fontes tributárias, compensação ambiental, Compensação Financeira pela Exploração de Recursos Minerais (CFEM), royalties de petróleo e gás natural; doações; empréstimos e trocas de dívida; patrocínio; pagamentos por serviços ambientais; licenças, certificados e papéis de mercado; e rendimentos obtidos com a aplicação de seu próprio patrimônio e outras fontes.

\section{Cooperação e parcerias}

O SISMUMA não representa um mero dispositivo político-administrativo isolado, mas sim uma ação integrada de largo espectro, destinada a transcender o âmbito local para interagir com as outras esferas da gestão ambiental, como a estadual, a federal e a de outros Municípios, com diversos atores envolvidos, como organizações não governamentais, setor privado, universidades, instituições de pesquisa e sociedade civil, entre outras.

Cabe ao Município estabelecer parcerias, "pois algumas questões ambientais extrapolam as fronteiras de um Município e condicionam a eficácia da solução à resolução cooperada do problema" (Anamma, 1999). Isto favorece o uso eficiente de recursos 
públicos e a otimização dos recursos humanos segundo o mote "somar recursos para multiplicar resultados". As parcerias podem valer-se de mecanismos como cooperações, convênios, intercâmbios, concessões, permissões, terceirizações, cogestões, entre outros, e podem envolver instrumentos de cooperação financeira, técnica, científica, tecnológica e também a cooperação com a sociedade em termos de participação.

O Ministério do Meio Ambiente, através de seu programa de fortalecimento do Sistema Nacional de Meio Ambiente, vem promovendo a integração do Simuma com os sistemas de gestão ambiental das demais esferas do governo, através da instalação de Comissões Tripartites, constituídas por representantes de órgãos ambientais dos níveis federal, estadual e municipal, com o objetivo de "constituir um espaço institucional de diálogo entre os entes federados com vistas a uma gestão compartilhada e descentralizada entre União, Estados e Municípios” (MMA, 2003).

Em 2002, segundo o IBGE (2005a), 45\% dos Municípios haviam firmado algum tipo de parceria com vistas a desenvolver ações na área ambiental. Destes, $30 \%$ o fizeram com órgãos públicos federais, $60 \%$ com órgãos públicos estaduais, 10\% com órgãos de outros Municípios, 17\% com instituições privadas, $4 \%$ com instituições internacionais, $16 \%$ com ONGs e $18 \%$ com universidades ou instituições de pesquisa. Além disso, 20\% das municipalidades informaram ainda participar de consórcio intermunicipal na área de meio ambiente, para a realização de objetivos de interesse comum por meio de obras, atividades e serviços comuns na região por eles abrangida, e $22 \%$ afirmaram possuir protocolo de transferência de atribuições com o órgão ambiental de seu estado. Uma pesquisa mais recente do IBGE, de 2008 , identificou que 59,9\% dos municípios participam de articulações intermunicipais, sendo que, destes, 74,0\% em Comitê de Bacia Hidrográfica, 32,5\% em Consórcio Intermunicipal e $25,5 \%$ em outros tipos de articulações (IBGE, 2008).

A articulação intermunicipal contribui para o fortalecimento dos mecanismos de gestão local ao promover a cooperação técnica, jurídica e administrativa necessárias à sua consolidação. Esta integração pode ser realizada também através da formação de consórcio intermunicipal, uma associação de
Municípios que pretende, por meio da ação conjunta de seus participantes, alcançar objetivos comuns, viabilizar recursos financeiros para a sua realização e maior capacitação e treinamento de equipes locais. Os Municípios podem recorrer aos consórcios para cooperar na preservação dos seus recursos naturais renováveis, bem como para participar de estudos e pesquisas sobre as potencialidades locais e elaborações de planos, programas e projetos. Nos casos em que o Município é incapaz de estruturar seu próprio sistema de gestão ambiental, o apoio à constituição de consórcios intermunicipais é um caminho promissor.

\section{Discussão e Conclusão}

O papel dos governos locais, antes vistos como mero prestadores de serviços, vem evoluindo, pósConstituição de 1988, para o de agentes do desenvolvimento local. Neste contexto, os Municípios necessitam assumir o seu papel constitucional de defesa e preservação do meio ambiente, tomando a decisão de envolver-se no tema e capacitando-se através da instituição de um Sistema Municipal de Meio Ambiente. O SISMUMA, conforme apresentado, é uma estrutura político-administrativa que em última instância visa a inserção do componente ambiental no processo de tomada de decisão local, por meio da formulação, implementação e avaliação de políticas ambientais e integração com outras políticas, considerando a realidade e potencialidade de cada região, em conformidade com os princípios de desenvolvimento sustentável.

Salienta-se que uma boa governança ambiental depende do "processo de negociação entre as diferentes partes interessadas, de forma a viabilizar a integração do componente ambiental no processo de tomada de decisão, orientado para o desenvolvimento em bases sustentáveis" (Philippi Jr e col., 2007). Somente desse modo, a esfera local conseguirá governabilidade (legitimidade) para suas ações e tomada de decisões em bases sustentáveis. A consolidação da governança ainda acaba com a dominação do Município pelas elites locais, ao inserir diversos atores do governo e da sociedade civil no processo de decisão, evitando que o poder de decisão seja pautado pelo interesse de uma minoria. 
A instituição do SISMUMA pelo governo municipal gera diversos benefícios ao Município. Um governo comprometido com o desenvolvimento sustentável possui menores riscos de ter seus projetos rejeitados e proporciona uma maior integração entre os seus diversos órgãos. O desenvolvimento de uma PMMA comprometida com os princípios da sustentabilidade potencializa a defesa e a preservação do meio ambiente local, impulsionando um desenvolvimento com preservação ambiental, inclusão social e crescimento econômico. A existência de um COMUMA no qual todos os atores estejam representados e possuam legitimidade aprimora o diálogo entre os diversos atores locais e minimiza os conflitos ambientais. Um OMMA estruturado intensifica a eficiência do processo de gestão ambiental local. E a criação do FMMA carrega para a área ambiental recursos financeiros.

Dos mais de cinco mil Municípios brasileiros, poucos foram os que tomaram caminhos sustentáveis e consolidados de gestão ambiental. Em outras palavras, a governança para a descentralização da gestão ambiental no Brasil ainda não é uma ideia concreta em boa parte dos municípios brasileiros (Azevedo e col., 2007). São inúmeras as dificuldades que os Municípios encontram na implantação e manutenção de seu Sistema Municipal de Meio Ambiente, porém é extremamente necessário avançar-se na sua consolidação. A disseminação dos SISMUMA nos Municípios brasileiros contribui com a produção de modelos alternativos de políticas centradas no enfrentamento dos déficits e desigualdades socioambientais, e apoiadas na inclusão de novos atores nos processos de decisão.

\section{Referências}

ANAMMA - Associação Nacional de Órgãos Municipais de Meio Ambiente. Municípios e meio ambiente: perspectivas para a municipalização da gestão ambiental no Brasil. São Paulo: ANAMMA, 1999 .

AZEVEDO, A.; PASQUIS, R.; BURSZTYN, M. A reforma do Estado, a emergência da descentralização e as políticas ambientais. Revista do Serviço Público, Brasília, n. 58, v. 1, jan./mar. 2007.
BRASIL. Lei n. 6.938, de 31 de agosto de 1981. Dispõe sobre a Política Nacional do Meio Ambiente, seus fins e mecanismos de formulação e aplicação, e dá outras providências. Diário Oficial da União, Brasília, DF, o2/o9/1981, p.16.519.

BRASIL. Lei n. 6.905, de 12 de fevereiro de 1998. Dispõe sobre as sanções penais e administrativas derivadas de condutas e atividades lesivas ao meio ambiente, e dá outras providências. Diário Oficial da União, Brasília, DF, 13/o2/1998, p.1.

BRASIL, F. P. D. As novas instâncias de participação cidadã e a gestão democrática das cidades. Texto para discussão n. 15. Belo Horizonte: Escola de Governo da Fundação João Pinheiro, 2005.

BRUSCHI, D. M.; et al. Manual de saneamento e proteção ambiental para os municípios. 3 ed., Belo Horizonte: Fundação Estadual do Meio Ambiente, 2002. v. 1.

CARVALHO, P. G. M.; et al. Gestão local e meio ambiente. Ambiente \& Sociedade, São Paulo, v. 8, n. 1, jan./jun. 2005.

CEPAM - Centro de Estudos e Pesquisas em Administração Municipal. Política municipal de meio ambiente: orientação para os municípios. 2. ed. São Paulo: CEPAM: 1992.

CEPAM - Centro de Estudos e Pesquisas em Administração Municipal. Gestão ambiental municipal: módulo básico. São Paulo: CEPAM, 2007.

CEZARE, J. P.; MALHEIROS, T. F.; PHILIPPI

JR, A. Avaliação de política ambiental e sustentabilidade: estudo de caso do município de Santo André - SP. Revista Engenharia Sanitária e Ambiental, Rio de Janeiro, v. 12, n. 4, p. 417-425, 2007.

FAMURS - Federação das Associações de Municípios do Rio Grande do Sul. Gestão pública municipal: orientações básicas nas ações municipais no meio ambiente; planejamento integrado, estratégico e sustentado - coletânia básica de legislação ambiental. Porto Alegre: Federação das Associações dos Municípios do RS, 2005 . 
IBGE - Instituto Brasileiro de Geografia e Estatística. Perfil dos municípios brasileiros: gestão pública 2001. Rio de Janeiro: IBGE, 2003.

IBGE, Instituto Brasileiro de Geografia e Estatística. Perfil dos municípios brasileiros: meio ambiente 2002. Rio de Janeiro: IBGE, 2005.

IBGE, Instituto Brasileiro de Geografia e Estatística. Perfil dos municípios brasileiros: gestão pública 2008. Rio de Janeiro: IBGE, 2008.

ICLEI, Local Governments for Sustainability. Mudanças Climáticas e Desenvolvimento Limpo: Oportunidades para Governos Locais - Um Guia do ICLEI. 2.005.

LITTLE, P. E. [org]. Políticas ambientais no Brasil: análises, instrumentos e experiências. São Paulo: Peirópólis; Brasília, DF: IIEB, 2003.

SOUZA, Elaine Castelo Branco; MAMEDE, Fani; FERREIRA, Fernanda do Socorro Santos; SILVA, Fernando Antonio Lyrio; SANTANA, Rodrigo Borges; ROLDAN, Rosa; LEITÃO, Sanderson Alberto Medeiros. Desafios da gestão ambiental nos municípios. Em Políticas ambientais no Brasil: análises, instrumentos e experiências. Organizador: Paul E. Little. São Paulo: Peirópolis; Brasília, DF: IIEB, 2.003.

MAZZOLENIS, E. Política municipal de meio ambiente: proposta e reflexões para uma sociedade sustentável. Jaboticabal: Fábrica da Palavra, 1998.
MINISTÉRIO DO MEIO AMBIENTE. Gabinete do Ministro. Portaria n. 473, de 9 de dezembro de 2003. Diário Oficial da União, Brasília, DF, 10/12/2003, p.95

MMA, Ministério do Meio Ambiente. Encontro Nacional de Colegiados Ambientais: Participação para a Sustentabilidade Ambiental. Brasília, 2.007 .

O ESTADO DE S. PAULO. Só um em cada cinco cidades tem dinheiro para governar. $O$ Estado de S. Paulo, São Paulo, 17 nov. 2007.

TATAGIBA, F. C. P; LEME, T. N. (Coord.). Fontes de recursos financeiros para a gestão ambiental pública: cenários e estratégias de captação para o funcionamento de fundos socioambientais.

Brasília: Rede Brasileira de Fundos Socioambientais, 2008. (Série Financiamento e Fomento Ambiental no Brasil, 2).

PHILIPPI Jr, A.; et al. Gestão ambiental municipal: subsídios para estruturação de sistema municipal de meio ambiente. Salvador: CRA, 2004a.

PHILIPPI JR, A.; SALLES, C. P.; MALHEIROS, T. F. Subsídios para o planejamento estratégico: fortalecimento da gestão ambiental municipal no corredor central da mata atlântica - Bahia. São Paulo: Faculdade de Saúde Pública; Núcleo de Informações em Saúde Ambiental da USP, 2004b.

PHILIPPI Jr, A.; MALHEIROS, T. F. Gestão ambiental local. In: SANTANNA, P. Planejamento urbano e avaliação do impacte na saúde. Coimbra: Universidade de Coimbra, 2007. 